\title{
Control of arbuscular mycorrhiza development by nutrient signals
}

\author{
Samy Carbonnel and Caroline Gutjahr* \\ Faculty of Biology, Genetics, University of Munich (LMU), Martinsried, Germany \\ ${ }^{*}$ Correspondence: caroline.gutjahr@Imu.de \\ Edited by: \\ Francis Michel Martin, National Institute for Agricultural Research, France \\ Reviewed by: \\ Soizic Rochange, Toulouse University, France \\ Pierre-Marc Delaux, University of Wisconsin-Madison, USA
}

Keywords: arbuscular mycorrhiza, nutrient signaling, phosphate, MYCS element, P1BS element, symbiosis

Inorganic phosphate $\left(\mathrm{P}_{\mathrm{i}}\right)$, the main form of phosphorus used by plants, is one of the most important limiting factors for plant growth. In the soil soluble $\mathrm{P}_{\mathrm{i}}$ that is readily available for uptake, occurs at very low concentrations (Schachtman et al., 1998). One adaptation of plants to low $\mathrm{P}_{\mathrm{i}}$ availability is the symbiosis with arbuscular mycorrhiza fungi (AMF) of the phylum Glomeromycota. The fungi efficiently take up phosphate and other mineral nutrients and deliver them to the host, in exchange for carbohydrates. Thereby, arbuscularmycorrhiza compatible plants have two $\mathrm{P}_{\mathrm{i}}$ uptake pathways, which are defined by different sets of phosphate transporters: a direct uptake pathway through the epidermis and root hairs, and a symbiotic uptake pathway for the $\mathrm{P}_{i}$ provided by the fungus (Smith and Smith, 2011).

For successful symbiosis the fungus colonizes the root. This involves initial recognition via diffusible molecules, hyphal docking to the root surface by a hyphopodium, re-differentiation of plant cells and their subsequent penetration by fungal hyphae and formation of highly branched fungal arbuscules in the root cortex, which release mineral nutrients to the host (Gutjahr and Parniske, 2013). Plants control the degree of arbuscular mycorrhiza (AM) colonization depending on their nutritional status and it has been repeatedly reported that under high $\mathrm{P}_{\mathrm{i}}$ supply, AM development is repressed (e.g., Menge et al., 1978; Braunberger et al., 1991; Balzergue et al., 2010; Breuillin et al., 2010). This suppressive effect of high $P_{i}$ on root colonization by AMF is partially overruled by nitrogen $(\mathrm{N})$ starvation, and to a lesser extent by potassium, calcium or iron starvation (Nouri et al., 2014), suggesting that plants control the symbiosis in function of their nutrient requirements according to Liebig's law of the minimum. The molecular mechanisms underlying the control of AM development by nutrient conditions are largely unknown. Conceptually, two scenarios are possible: AM development might be actively suppressed at high $\mathrm{P}_{\mathrm{i}}$ conditions (Figures 1A,C). Alternatively or in addition, root cells might be conditioned by $\mathrm{P}_{\mathrm{i}}$ starvation to actively promote AM formation (Figures 1B,D). At sufficient $\mathrm{P}_{\mathrm{i}}$ supply this promotion might be simply absent. Here we examine the available literature for evidence for one or the other scenario.

Although several nutrients influence AM development (Nouri et al., 2014) most research has focused on the role of $\mathrm{P}_{i}$. Hyphopodium numbers on maize roots were inversely correlated with the $\mathrm{P}_{\mathrm{i}}$ status of the shoot (Braunberger et al., 1991), indicating that AM suppression by high $\mathrm{P}_{\mathrm{i}}$ occurs systemically. Indeed, split root experiments in pea and Petunia, showed an inhibition of AM colonization in the entire root system, even if only one half of the root system was fertilized with a high $\mathrm{P}_{\mathrm{i}}$ concentration and the other half maintained a low $\mathrm{P}_{\mathrm{i}}$ content (Balzergue et al., 2010; Breuillin et al., 2010). This calls for a long distance signal traveling from the shoot to the root to regulate AM colonization that might either suppress $\mathrm{AM}$ at high $\mathrm{P}_{\mathrm{i}}$ or promote its development at low $\mathrm{P}_{\mathrm{i}}$. Candidates for long-distance signaling molecules could be members of the miR399 family since they play a well-established role in systemic $\mathrm{P}_{\mathrm{i}}$-starvation signaling (Lin et al., 2008; Pant et al., 2008; Gu et al., 2011). Interestingly, upon AM colonization, the expression of some miR399 family members was increased in Medicago and tomato leaves (Branscheid et al., 2010; Gu et al., 2014). Consistently, transcript levels of the miR399 target, $\mathrm{PHO} 2$ an ubiquitin E2 conjugase, that mediates the degradation of proteins required for phosphate starvation responses (Liu et al., 2012; Park et al., 2014), remained low (Branscheid et al., 2010). It was postulated that increased expression of miR399 family members might serve to keep phosphate starvation responses high to allow continuous colonization, in spite of increased shoot phosphate content resulting from functional symbiosis (Branscheid et al., 2010). However, miR399 over-expression failed to support colonization under high $\mathrm{P}_{\mathrm{i}}$ supply (Branscheid et al., 2010), indicating that other regulatory mechanisms link AM development to the nutrient status of the plant.

Plant endosymbiosis (AM and root nodule symbiosis) development requires a common set of genes called common SYM genes. Their protein products belong to a signal transduction cascade that is triggered by perception of fungal signals (Myc factors) through receptor-likekinases (Gough and Cullimore, 2011). Myc factor perception induces nuclear $\mathrm{Ca}^{2+}$-spiking that is decoded by a nuclear localized calcium-calmodulin kinase (CCaMK) and leads to transcriptional activation of symbiosis-related genes by 


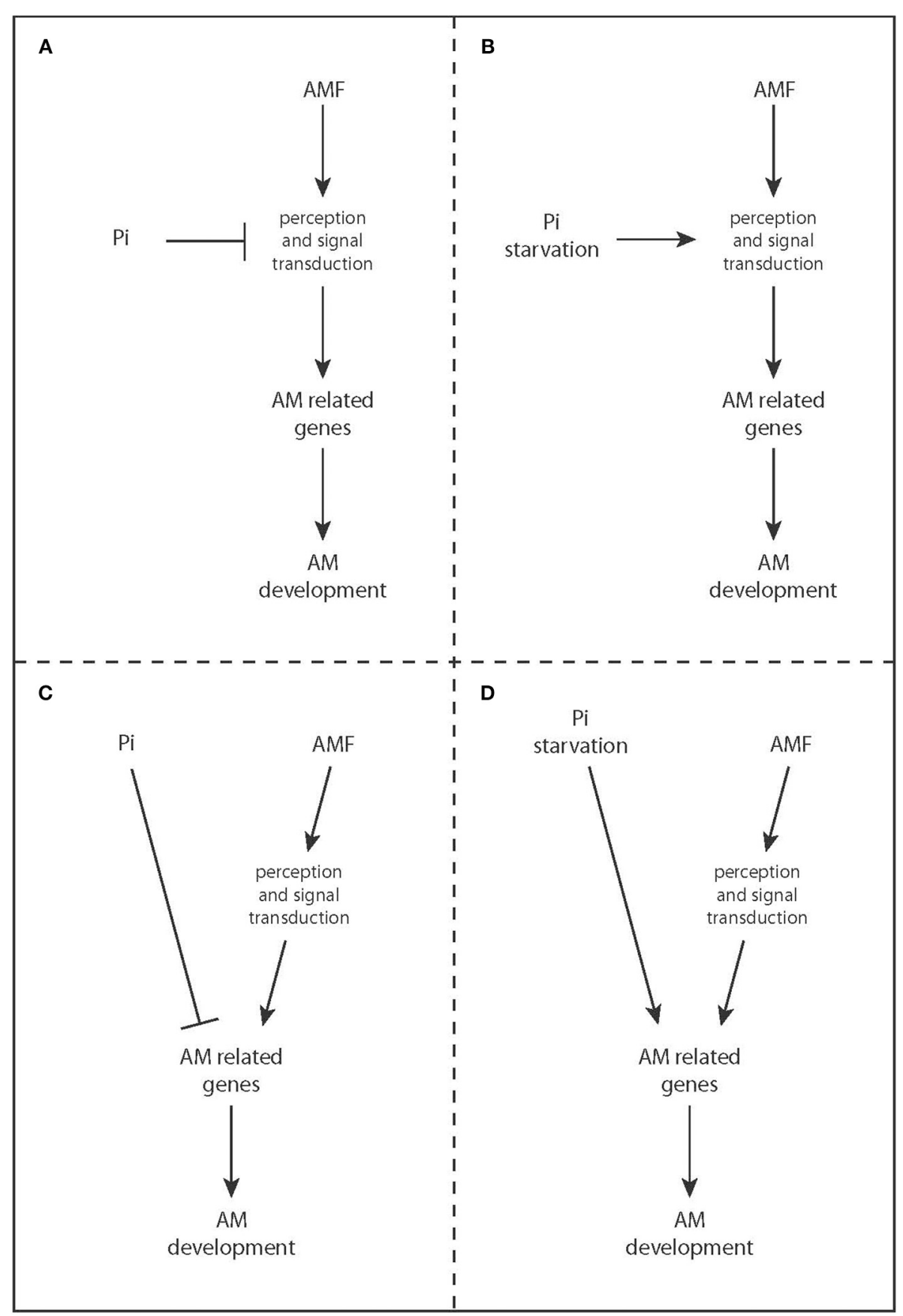

FIGURE 1 | Hypothetical models of how phosphate signaling might control AM development. Other nutrients might influence AM development in a similar fashion as shown here for $\mathrm{P}_{\mathrm{i}} . \mathbf{( A , B )}$ Perception of Myc factors, signal transduction through common SYM network or other symbiosis signaling pathways are directly targeted by $\mathrm{P}_{\mathrm{i}}$ signaling. (C,D) $\mathrm{P}_{\mathrm{i}}$ and symbiosis signaling co-regulate downstream genes that are required for AM development and maintenance (e.g., symbiotic phosphate transporters). (A-C) Signaling events that are generated in response to a high $\mathrm{P}_{i}$ status of the shoot actively inhibit AM development. (B-D) $P_{i}$ starvation signaling is required to promote $\mathrm{AM}$ colonization. the transcription factor CYCLOPS (Genre et al., 2013; Singh et al., 2014). One potential explanation for suppression of AM development at high $\mathrm{P}_{\mathrm{i}}$ could be the repression of common SYM signaling (Figure 1A). In Petunia, the expression of the putative ortholog of NOD FACTOR RECEPTOR 5, which is required for Nod factor perception in legumes, is decreased at high $\mathrm{P}_{\mathrm{i}}$ (Breuillin et al., 2010). Although Petunia does not form root nodule symbioses this receptor might be involved in perception of fungal signaling molecules and reduced receptor availability might lead to abortion of colonization (Figure 1A, Breuillin et al., 2010). However, the expression of downstream common SYM genes involved in 
the generation and interpretation of $\mathrm{Ca}^{2+}$ spiking is not affected (Breuillin et al., 2010) and high $P_{i}$ did not reduce the ability of Medicago rhizodermis cells to trigger nuclear $\mathrm{Ca}^{2+}$-spiking in response to rare hyphopodia or germinating spore exudates (Balzergue et al., 2013). Therefore, it is unlikely that receptor availability at the rhizodermis limits colonization. However, it remains open whether it affects colonization in the cortex (Breuillin et al., 2010; Op Den Camp et al., 2011). Alternatively, $\mathrm{P}_{\mathrm{i}}$ might alter the signal transduction cascade either downstream of calcium spiking or influence a pathway that operates in parallel with common SYM signaling (Figure 1).

Good candidates for such downstream or parallel mechanisms are phytohormone signaling modules, as they steer developmental responses to the nutrient environment (Rubio et al., 2009) and regulate AM formation (Foo et al., 2013; Bucher et al., 2014; Gutjahr, 2014). For example strigolactones are exuded into the rhizosphere and stimulate germination, hyphal branching and metabolic activity of AM fungi (Akiyama et al., 2005; Besserer et al., 2006, 2008), which increases AM colonization (Gomez-Roldan et al., 2008; Foo et al., 2012; Gutjahr et al., 2012; Kohlen et al., 2012; Kretzschmar et al., 2012; Yoshida et al., 2012). At high $P_{i}$ conditions the number of transcripts encoding strigolactone biosynthesis enzymes as well as strigolactone exudation from roots are reduced (Yoneyama et al., 2007; LópezRáez et al., 2008; Balzergue et al., 2010, 2013; Breuillin et al., 2010). However, exogenous supply of the synthetic strigolactone GR24 could not restore colonization at high $\mathrm{P}_{\mathrm{i}}$ availability (Balzergue et al., 2010; Breuillin et al., 2010), indicating that the reduced strigolactone exudation is not the main reason for low AM colonization. Gibberellins (GAs) negatively regulate AM development. In Medicago and pea exogenous GA treatment of roots blocked arbuscule formation but did not affect the colonization with intraradical hyphae (Floss et al., 2013; Foo et al., 2013), while in rice it generally reduced intraradical colonization (Yu et al., 2014). Consistently, DELLA proteins, which are repressors of GA signaling are required for AM development (Floss et al., 2013; Foo et al., 2013; Yu et al., 2014). Arabidopsis plants grown at $\mathrm{P}_{\mathrm{i}}$ starvation conditions accumulate DELLA proteins and reduced levels of GA (Jiang et al., 2007). Thus, the GA signaling module has the potential to regulate AM development and in particular arbuscule formation according to the plant phosphate status (Floss et al., 2013). Interestingly, arbuscule formation of the L. japonicus common SYM mutant cyclops can be restored by overexpression of a resistant DELLA version. The DELLA/GA module is therefore a good candidate regulator of arbuscule development either downstream of or in parallel with common SYM signaling (Floss et al., 2013; Gutjahr, 2014). However, it remains to be tested whether transgenic expression of a resistant DELLA can counteract the negative impact of high $\mathrm{P}_{\mathrm{i}}$ supply on AM symbiosis.

Symbiotic $\mathrm{P}_{\mathrm{i}}$ uptake occurs in cortex cells that are colonized by arbuscules (Javot et al., 2007a). Arbuscules are surrounded by a plant derived periarbuscular membrane that hosts a specific set of membrane proteins (Pumplin and Harrison, 2009). Importantly, it contains symbiotic phosphate transporters (PT4/PT11), which import phosphate ions that are released by the arbuscule into the plant cell (Javot et al., 2007b; Yang et al., 2012). Medicago pt4 and rice pt11 mutants revealed that PT4/PT11 is not only essential for AM-mediated phosphate uptake but also for arbuscule maintenance (Javot et al., 2007b; Yang et al., 2012) demonstrating that $\mathrm{P}_{\mathrm{i}}$ import is crucial for wild-type arbuscule dynamics. It has been suggested that the $P_{i}$ ion itself could act as a local, cell-autonomous signal that triggers accommodation and maintenance of the arbuscule by the host cell (Javot et al., 2007a; Yang and Paszkowski, 2011). This notion is supported by the rice pt13 mutant, which is deficient in a second AM-induced phosphate transporter called PT13. It is not impaired in symbiotic phosphate uptake, but in arbuscule maintenance. Thus, OsPT13 might act as a $P_{i}$ sensor rather than a transporter (Yang et al., 2012). Arbuscule lifespan in roots of the Medicago pt4 mutant is restored by growing the plant at low nitrogen $(\mathrm{N})$ concentrations (Javot et al., 2011). This indicates that not only $\mathrm{P}_{\mathrm{i}}$ - but also $\mathrm{N}$-delivery can support arbuscule maintenance in a cell-autonomous fashion.
Analysis of the promoter regions of symbiotic PTs in different species revealed two conserved cis-elements called MYCS (or CTTC) and P1BS that are often located close to each other (Karandashov et al., 2004; Chen et al., 2011). Deletion of each of these elements from PT promoters driving a GUS reporter gene showed that they are both essential for colonization-responsive promoter activation (Chen et al., 2011), suggesting that at least 2 transcriptions factors (TFs) coregulate the expression of symbiotic PTs. The MYCS element is over-represented in mycorrhiza-regulated genes and four repeats of the MYCS element alone are sufficient to drive GUS-expression in colonized areas of the root (Lota et al., 2013). Thus, the P1BS element is dispensable when MYCS is taken out of context. The P1BS motif is common to many promoters of $P_{i}$ starvation-induced genes and is targeted by central regulators of $P_{i}$ starvation responses, the MYB transcription factor PHR1 and its homologs (Bustos et al., 2010). Thus, promoter induction of symbiotic phosphate transporters and other mycorrhiza-responsive genes, likely requires simultaneous activation by symbiosis signaling and $\mathrm{P}_{\mathrm{i}}$ starvation signaling (Figure 1D). Repressed expression of a transgene containing 4xMYCS-GUS after fertilization of colonized transgenic roots of Lotus japonicus with high $\mathrm{P}_{\mathrm{i}}$ for 2 weeks seems to contradict this hypothesis (Lota et al., 2013). However, in Petunia it has been shown earlier that such a long period of phosphate replenishment leads to decreased root colonization while expression of a symbiotic PT gene is already suppressed after 2-4 days of high $\mathrm{P}_{\mathrm{i}}$ supply (Breuillin et al., 2010). Therefore, 2 weeks after $P_{i}$ replenishment, MYCS activation is probably indirectly affected due to fungal senescence and cessation of symbiotic signaling. Nevertheless, the important role of symbiotic PTs in AM symbiosis maintenance (Javot et al., 2007b; Yang et al., 2012) and their transcriptional regulation by $\mathrm{P}_{\mathrm{i}}$ conditions (Nagy et al., 2009; Breuillin et al., 2010) makes them possible targets of AM developmental control by nutrients. Taking together this assumption with the phenotype of pt4/pt11 and pt13 mutants creates an important paradox: on one hand systemic $\mathrm{P}_{\mathrm{i}}$ 
starvation is required to allow the expression of symbiotic PTs; on the other hand symbiotic PTs themselves need to deliver the phosphate that will allow arbuscule formation and maintenance (Javot et al., 2007b; Breuillin et al., 2010; Yang et al., 2012). How plants integrate these opposing situations-i.e., simultaneous requirement of systemic $\mathrm{P}_{\mathrm{i}}$ starvation and of cell-autonomous symbiotic $\mathrm{P}_{\mathrm{i}}$ deliveryrepresents a very intriguing question for future research.

In summary, the mechanisms of how AM development is controlled by nutrient signaling are yet elusive. However, circumstantial evidence suggests that control occurs at multiple levels, and includes nutrient, phytohormone and symbiosis as well as systemic and cell-autonomous signaling. The signal operating in systemic shoot-to-root $\mathrm{P}_{\mathrm{i}}$ signaling remains to be found. Strigolactone exudation, the DELLA/GA signaling module and the P1BS element-binding transcription factor are excellent candidates for local mediators between nutrient status and AM development in the root. Additionally, the co-occurrence of MYCS and P1BS cis-elements in AM-inducible promoters strongly suggests that $\mathrm{P}_{\mathrm{i}}$ starvation signaling and AM signaling are required simultaneously for symbiotic gene expression and consequently colonization (Figure 1D). Transgenic manipulation using dominant negative and dominant active candidate signaling components with the aim to restore AM development at sufficient $\mathrm{P}_{\mathrm{i}}$ should help to pinpoint the important regulators and to detangle how plants integrate symbiosis, phytohormone and nutrient signaling to control AM development in function of their nutrient status.

\section{ACKNOWLEDGMENTS}

Research of the authors is supported by the collaborative research center "Molecular mechanisms regulating yield and yield stability in plants" (SFB924) of the German Research Foundation (DFG).

\section{REFERENCES}

Akiyama, K., Matsuzaki, K., and Hayashi, H. (2005). Plant sesquiterpenes induce hyphal branching in arbuscular mycorrhizal fungi. Nature 435, 824-827. doi: 10.1038/nature 03608

Balzergue, C., Chabaud, M., Barker, D. G., Bécard, G., and Rochange, S. (2013). High phosphate reduces host ability to develop arbuscular mycorrhizal symbiosis without affecting root calcium spiking responses to the fungus. Front. Plant Sci. 4:426. doi: 10.3389/fpls.2013. 00426

Balzergue, C., Puech-Pagès, V., Bécard, G., and Rochange, S. F. (2010). The regulation of arbuscular mycorrhizal symbiosis by phosphate in pea involves early and systemic signalling events. J. Exp. Bot. 62, 1049-1060. doi: 10.1093/ jxb/erq335

Besserer, A., Becard, G., Jauneau, A., Roux, C., and Sejalon-Delmas, N. (2008). GR24, a synthetic analog of strigolactones, stimulates the mitosis and growth of the arbuscular mycorrhizal fungus Gigaspora rosea by boosting its energy metabolism. Plant Physiol. 148, 402-413. doi: 10.1104/pp.108.121400

Besserer, A., Puech-Pagés, V., Kiefer, P., GomezRoldan, V., Jauneau, A., Roy, S., et al. (2006). Strigolactones stimulate arbuscular mycorrhizal fungi by activating mitochondria. PLoS Biol. 4:e226. doi: 10.1371/journal.pbio.0040226

Branscheid, A., Sieh, D., Pant, B. D., May, P., Devers, E. A., Elkrog, A., et al. (2010). Expression pattern suggests a role of MiR399 in the regulation of the cellular response to local Pi increase during arbuscular mycorrhizal symbiosis. Mol. Plant Microbe Interact. 23, 915-926. doi: 10.1094/mpmi23-7-0915

Braunberger, P. G., Miller, M. H., and Peterson, R. L. (1991). Effect of phosphorous nutrition on morphological characteristics of vesiculararbuscular mycorrhizal colonization of maize. New Phytol. 119, 107-113. doi: 10.1111/j.14698137.1991.tb01013.x

Breuillin, F., Schramm, J., Hajirezaei, M., Ahkami, A., Favre, P., Druege, U., et al. (2010). Phosphate systemically inhibits development of arbuscular mycorrhiza in Petunia hybrida and represses genes involved in mycorrhizal functioning. Plant J. 64, 1002-1017. doi: 10.1111/j.1365-313X.2010.04385.x

Bucher, M., Hause, B., Krajinski, F., and Küster, H. (2014). Through the doors of perception to function in arbuscular mycorrhizal symbioses. New Phytol. doi: 10.1111/nph.12862. [Epub ahead of print].

Bustos, R., Castrillo, G., Linhares, F., Puga, M. I., Rubio, V., Pérez-Pérez, J., et al. (2010). A central regulatory system largely controls transcriptional activation and repression responses to phosphate starvation in Arabidopsis. PLoS Genet. 6:e1001102. doi: 10.1371/journal.pgen. 1001102

Chen, A., Gu, M., Sun, S., Zhu, L., Hong, S., and $\mathrm{Xu}, \mathrm{G}$. (2011). Identification of two conserved cis-acting elements, MYCS and P1BS, involved in the regulation of mycorrhizaactivated phosphate transporters in eudicot species. New Phytol. 189, 1157-1169. doi: 10.1111/j.1469-8137.2010.03556.x

Floss, D. S., Levy, J. G., Lévesque-Tremblay, V., Pumplin, N., and Harrison, M. J. (2013). DELLA proteins regulate arbuscule formation in arbuscular mycorrhizal symbiosis. Proc. Natl. Acad. Sci. U.S.A. 110, E5025-E5034. doi: 10.1073/pnas. 1308973110

Foo, E., Ross, J. J., Jones, W. T., and Reid, J. B. (2013). Plant hormones in arbuscular mycorrhizal symbioses: an emerging role for gibberellins. Ann. Bot. 111, 769-779. doi: 10.1093/aob/mct041

Foo, E., Yoneyama, K., Hugill, C., Quittenden, L., and Reid, J. (2012). Strigolactones and the regulation of pea symbioses in response to nitrate and phosphate deficiency. Mol. Plant 6, 76-87. doi: $10.1093 / \mathrm{mp} / \mathrm{sss} 115$

Genre, A., Chabaud, M., Balzergue, C., Puech-Pagès, V., Novero, M., Rey, T., et al. (2013). Short-chain chitin oligomers from arbuscular mycorrhizal fungi trigger nuclear $\mathrm{Ca}^{2+}$ spiking in Medicago truncatula roots and their production is enhanced by strigolactone. New Phytol. 198, 190-202. doi: 10.1111/nph.12146

Gomez-Roldan, V., Fermas, S., Brewer, P. B., PuechPages, V., Dun, E. A., Pillot, J.-P., et al. (2008) Strigolactone inhibition of shoot branching. Nature 455, 189-194. doi: 10.1038/nature07271

Gough, C., and Cullimore, J. (2011). Lipochitooligosaccharide signaling in endosymbiotic plant-microbe interactions. Mol. Plant Microbe Interact. 24, 867-878. doi: 10.1094/mpmi-01-11-0019

Gu, M., Chen, A., Dai, X., Liu, W., and Xu, G. (2011). How does phosphate status influence the development of the arbuscular mycorrhizal symbiosis? Plant Signal. Behav. 6, 1300-1304. doi: 10.4161/psb.6.9.16365

Gu, M., Liu, W., Meng, Q., Zhang, W., Chen, A., Sun, S., et al. (2014). Identification of microRNAs in six solanaceous plants and their potential link with phosphate and mycorrhizal signalings. J. Integr. Plant Biol. doi: 10.1111/jipb.12233. [Epub ahead of print].

Gutjahr, C. (2014). Phytohormone signaling in arbuscular mycorhiza development. Curr. Opin. Plant Biol. 20, 26-34. doi: 10.1016/j.pbi.2014.04.003

Gutjahr, C., and Parniske, M. (2013). Cell and developmental biology of the arbuscular mycorrhiza symbiosis. Annu. Rev. Cell Dev. Biol. 29, 593-617. doi: 10.1146/annurev-cellbio-101512-122413

Gutjahr, C., Radovanovic, D., Geoffroy, J., Zhang, Q., Siegler, H., Chiapello, M., et al. (2012). The half-size ABC transporters STR1 and STR2 are indispensable for mycorrhizal arbuscule formation in rice. Plant J. 69, 906-920. doi: 10.1111/j.1365313X.2011.04842.x

Javot, H., Penmetsa, R. V., Breuillin, F., Bhattarai, K. K., Noar, R. D., Gomez, S. K., et al. (2011). Medicago truncatula mtpt4 mutants reveal a role for nitrogen in the regulation of arbuscule degeneration in arbuscular mycorrhizal symbiosis. Plant J. 68, 954-965. doi: 10.1111/j.1365313X.2011.04746.x

Javot, H., Pumplin, N., and Harrison, M. (2007a). Phosphate in the arbuscular mycorrhizal symbiosis: transport properties and regulatory roles. Plant Cell Environ. 30, 310-322. doi: 10.1111/j.13653040.2006.01617.x

Javot, H., Varma Penmetsa, R., Terzaghi, N., Cook, D. R., and Harrison, M. J. (2007b). A Medicago truncatula phosphate transporter indispensible for the arbuscular mycorrhizal symbiosis. Proc. Natl. Acad. Sci. U.S.A. 104, 1720-1725. doi: 10.1073/pnas.0608136104

Jiang, C., Gao, X., Liao, L., Harberd, N. P., and Fu, X. (2007). Phosphate starvation root architecture and anthocyanin accumulation responses are modulated by the gibberellin-DELLA signaling pathway 
in Arabidopsis. Plant Physiol. 145, 1460-1470. doi: 10.1104/pp.107.103788

Karandashov, V., Nagy, R., Wegmuller, S., Amrhein, N., and Bucher, M. (2004). Evolutionary conservation of a phosphate transporter in the arbuscular mycorrhizal symbiosis. Proc. Natl. Acad. Sci. U.S.A. 101, 6285-6290. doi: 10.1073/pnas.0306 074101

Kohlen, W., Charnikhova, T., Lammers, M., Pollina, T., Tóth, P., Haider, I., et al. (2012). The tomato CAROTENOID CLEAVAGE DIOXYGENASE8 (SICCD8) regulates rhizosphere signaling, plant architecture and affects reproductive development through strigolactone biosynthesis. New Phytol. 196, 535-547. doi: 10.1111/j.1469-8137.2012.04265.x

Kretzschmar, T., Kohlen, W., Sasse, J., Borghi, L., Schlegel, M., Bachelier, J. B., et al. (2012). A petunia $\mathrm{ABC}$ protein controls strigolactone-dependent symbiotic signalling and branching. Nature 483, 341-344. doi: 10.1038/nature10873

Lin, S. I., Chiang, S. F., Lin, W. Y., Chen, J. W., Tseng, C. Y., Wu, P. C., et al. (2008). Regulatory network of microRNA399 and PHO2 by systemic signaling. Plant Physiol. 147, 732-746. doi: 10.1104/pp.108.116269

Liu, T. Y., Huang, T. K., Tseng, C. Y., Lai, Y. S., Lin, S. I., Lin, W. Y., et al. (2012). PHO2-dependent degradation of PHO1 modulates phosphate homeostasis in Arabidopsis. Plant Cell 24, 2168-2183. doi: 10.1105/tpc.112.096636

López-Ráez, J. A., Charnikhova, T., Gómez-Roldán, V., Matusova, R., Kohlen, W., De Vos, R., et al. (2008). Tomato strigolactones are derived from carotenoids and their biosynthesis is promoted by phosphate starvation. New Phytol. 178, 863-874. doi: 10.1111/j.1469-8137.2008.02406.x

Lota, F., Wegmüller, S., Buer, B., Sato, S., Bräutigam, A., Hanf, B., et al. (2013). The cis-acting CTTCP1BS module is indicative for gene function of LjVTI12, a Qb-SNARE protein gene, required for arbuscule formation in Lotus japonicus. Plant J. 74, 280-293. doi: 10.1111/tpj.12120

Menge, J. A., Steirle, D., Bagyaraj, D. J., Johnson, E. L. V., and Leonard, R. T. (1978). Phosphorus concentrations in plants responsible for inhibition of mycorrhizal infection. New Phytol. 80, 575-578. doi: 10.1111/j.1469-8137.1978.tb 01589.x

Nagy, R., Drissner, D., Amrhein, N., Jakobsen, I., and Bucher, M. (2009). Mycorrhizal phosphate uptake pathway in tomato is phosphorus-repressible and transcriptionally regulated. New Phytol. 181, 950-959. doi: 10.1111/j.1469-8137.2008. 02721.x

Nouri, E., Breuillin-Sessoms, F., Feller, U., and Reinhardt, D. (2014). Phosphorus and nitrogen regulate arbuscular mycorrhizal symbiosis in Petunia hybrida. PLoS ONE 9:e90841. doi: 10.1371/journal.pone.0090841

Op Den Camp, R., Streng, A., De Mita, S., Cao, Q. Polone, E., Liu, W., et al. (2011). LysM-type mycorrhizal receptor recruited for rhizobium symbiosis in nonlegume Parasponia. Science 331, 909-912. doi: 10.1126/science.1198181

Pant, B. D., Buhtz, A., Kehr, J., and Scheible, W. R. (2008). MicroRNA399 is a long-distance signal for the regulation of plant phosphate homeostasis. Plant J. 53, 731-738. doi: 10.1111/j.1365-313X.2007.03363.x

Park, B. S., Seo, J. S., and Chua, N. H. (2014). NITROGEN LIMITATION ADAPTATION recruits PHOSPHATE2 to target the phosphate transporter PT2 for degradation during the regulation of Arabidopsis phosphate homeostasis. Plant Cell 26, 454-464. doi: 10.1105/tpc.113.120311

Pumplin, N., and Harrison, M. J. (2009). Livecell imaging reveals periarbuscular membrane domains and organelle location in Medicago truncatula roots during arbuscular mycorrhizal symbiosis. Plant Physiol. 151, 809-819. doi: 10.1104/pp.109.141879

Rubio, V., Bustos, R., Irigoyen, M. L., Cardona-Lopez, X., Rojas-Triana, M., and Paz-Ares, J. (2009). Plant hormones and nutrient signaling. Plant Mol. Biol. 69, 361-373. doi: 10.1007/s11103-008-9380-y

Schachtman, D. P., Reid, R. J., and Ayling, S. M. (1998). Phosphorus uptake by plants: from soil to cell. Plant Physiol. 116, 447-453. doi: 10.1104/pp.116.2.447

Singh, S., Katzer, K., Lambert, J., Cerri, M., and Parniske, M. (2014). CYCLOPS, a DNA-binding transcriptional activator, orchestrates symbiotic root nodule development. Cell Host Microbe 15, 139-152. doi: 10.1016/j.chom.2014.01.011

Smith, S. E., and Smith, F. A. (2011). Roles of arbuscular mycorrhizas in plant nutrition and growth: new paradigms from cellular to ecosystem scales. Annu. Rev. Plant Biol. 62, 227-250. doi: 10.1146/annurevarplant-042110-103846

Yang, S.-Y., Grønlund, M., Jakobsen, I., Grotemeyer, M. S., Rentsch, D., Miyao, A., et al. (2012).
Nonredundant regulation of rice arbuscular mycorrhizal symbiosis by two members of the PHOSPHATE TRANSPORTER1 gene family. Plant Cell 24, 4236-4251. doi: 10.1105/tpc.112.104901

Yang, S.-Y., and Paszkowski, U. (2011). Phosphate import at the arbuscule: just a nutrient? $\mathrm{Mol}$. Plant Microbe Interact. 24, 1296-1299. doi: 10.1094/mpmi-06-11-0151

Yoneyama, K., Xie, X., Kusumoto, D., Sekimoto, H., Sugimoto, Y., Takeuchi, Y., et al. (2007). Nitrogen deficiency as well as phosphorus deficiency in sorghum promotes the production and exudation of 5-deoxystrigol, the host recognition signal for arbuscular mycorrhizal fungi and root parasites. Planta 227, 125-132. doi: 10.1007/s00425007-0600-5

Yoshida, S., Kameoka, H., Tempo, M., Akiyama, K., Umehara, M., Yamaguchi, S., et al. (2012). The D3 F-box protein is a key component in host strigolactone responses essential for arbuscular mycorrhizal symbiosis. New Phytol. 196, 1208-1216. doi: 10.1111/j.1469-8137.2012. 04339.x

Yu, N., Luo, D., Zhang, X., Liu, J., Wang, W., Jin, Y., et al. (2014). A DELLA protein complex controls the arbuscular mycorrhizal symbiosis in plants. Cell Res. 24, 130-133. doi: 10.1038/cr.2013.167

Conflict of Interest Statement: The authors declare that the research was conducted in the absence of any commercial or financial relationships that could be construed as a potential conflict of interest.

Received: 21 July 2014; accepted: 26 August 2014; published online: 11 September 2014.

Citation: Carbonnel S and Gutjahr C (2014) Control of arbuscular mycorrhiza development by nutrient signals. Front. Plant Sci. 5:462. doi: 10.3389/fpls.2014.00462

This article was submitted to Plant Physiology, a section of the journal Frontiers in Plant Science.

Copyright (c) 2014 Carbonnel and Gutjahr. This is an open-access article distributed under the terms of the Creative Commons Attribution License (CC BY). The use, distribution or reproduction in other forums is permitted, provided the original author(s) or licensor are credited and that the original publication in this journal is cited, in accordance with accepted academic practice. No use, distribution or reproduction is permitted which does not comply with these terms. 